over ninety days in all, the "glare" was of constant occurrence. By the arrival of O.S.S. Mariposa from San Francisco, December I to 8, I am happily able also to trace a continuous line of these phenomena hence to that point. They were not observed there until about November 23. Two of our leading citizens who came down by the Mariposa assure me that the appearances there were identical with ours, and further that they were of frequent recurrence during the whole passage. We thus prove a continuous chain of these phenomena from New Zealand to California.

Permit me to call special attention to the very peculiar corona or halo extending from $20^{\circ}$ to $30^{\circ}$ from the sun, which bas been visible every day with us, and all day, of whitish haze, with sinkish tint, shading off into lilac or purple against the blue. I have seen no notice of this corona observed elsewhere. It is hardly a conspicuous object.

The long continuance and extending diffusion of this haze or dry fog seems to justify expectation that it may become visible around the globe, and give ample opportunity for investigation.

Although not seen in San Francisco until November 23, it was brilliant in Santa Barbara on October I4. A rapid upper current seems to have borne it in a belt within the tropics in a very few days, leaving a slow diffusion to extend it to the tem. perate zone. Australia is perhaps an example of this.

I trust this letter may be a useful contribution towards a complete history of the diffusion of this very peculiar element around the globe. A good record of dates of earliest appearances might contribute something to our limited knowledge of currents in upper strata of the atmosphere.

Honolulu, December 14, I883

Sereno E. Bishop

[We have already referred to Mr. Bishop's letters in the Honolulu journal, but give here the following extract from his article in the Hawaiian Annual:-

"It now seems probable that the enormous projections of gaseous and other matter from Krakatoa have been borne by the upper currents and diffused throughout a belt of half the earth's circumference, and not improbably, as careful observation may yet establish, even entirely around the globe. This implies an amount of matter discharged that seems incredible. We learn, however, that the ocean was thickly and closely covered with floating pumice for hundreds of miles from the crater. A steamer I50 miles distant reports her barometer falling and rising half an inch every two or three minutes! This almost incredible statement implies a terrific undulation of the atmosphere, such as could only be produced by a vast and continuous jet of gas projected upwards beyond the limits of the atmosphere, and driving the air in vast waves in every direction. So abnormal and gigantic a force may well have propagated not only its tidal waves as it did across the Pacific, but it may also have transmitted its portentous and lurid vapours to belt the globe with flaming skies."]

FOR the last two months these appearances have in this province excited no small wonder and admiration, not unaccompanied in some cases with awe and dismal forebodings of impending calamity. As an example of what has been witnessed in greater or less intensity almost every morning and evening, about an hour before sunrise and after sunset, I may instance what was observed on the evening of the 29th and morning of the 3 oth ult. The ground from my residence rises towards the south and west, and the city of Fredericton lies towards the north-east, on a flat roo feet lower, and at a distance of half a mile or more. On the evening in question, at an hour after sunset, the red glow in the sky was very conspicuous, and seemed to light up the whole heavens, so that the bouses in the city were distinctly seen by the reflection from their sides, and the intervening snow appeared of an orange colour. It was bright enough to suggest the impression of a second sunset. Next morning at an hour before sunrise the deep red glow was equally decided.

Fredericton, New Brunswick, January 3

IN response to your note in NATURE of December 13, I883 (p. I 57), I beg to inform you that the recent red sunsets have been especially observed by me on the following occasions:-

Noveraber $3^{\circ}$, 1883 , lasting until $5.30 \mathrm{p.m}$.; barometer at I c'clock $30^{\circ} 22$ inches, at 9 p.m. $30 \cdot 10$.

January 2, I 884 , lasting until 7.30 p.m. ; barometer at I p.m. $30^{\circ} 4$, at 9 p.m. $30^{\circ} 43$.
January 3, I884; Barometer at I p.m. 30.30, at 9 p.m. $30^{\circ} 23$.

On several other occasions the same phenomenon has been observed in a less degree.

Krasnicza Wola, Grodzisk, near Warsaw, January II

THE "red glow" has again been very brilliant here on the evenings of January 9 and 10 , as well as on the morning of January io. On the following morning, January II, the sky being likewise very clear, I confidently expected another display, but to my astonishment no trace of red did appear, the sun rising after an ordinary twilight of pale yellow. During the night a strong south wind had set in, which prevailed through the whole day, with extraordinary transparency of the air. In the evening clouds arose in the west, at first showing the red marginal colouring of ordinary sunsets, but later on there came again, distinctly higher than even the cirri, a very brilliant and lasting red luminosity.

It would be interesting to know whether at other places too the phenomena in question had been, as it were, suspended on the morning of January $\mathbf{I} \mathbf{1}$, in spite of a clear sky, or whether such a suspension had occurred on other days under similar meteorological circumstances.

Freiburg, Badenia, January I2

THE last two days and nights here have been very fine with sunrises and sunsets as already described. This evening especially the colours were most brilliant, and did not fade away until at least an hour after sunset. It may interest those who are trying to account for this extraordinary appearance of the sky to know that here it has been followed by excessive rain and very bad weather. During December we had 9.57 against an average for the last twenty-two years of 4.46 inches. The greatest December rainfall registered at our Scutari Cemetery was 10.36 in 1862, the least being one inch in 1868 . A printer's error makes me speak, in my letter of December 2r, of a crescent moon "eighteen" days instead of 1.8 day old.

W. E. J.

Constantinople, January ir

\section{Dust Atmosphere of China}

IN the remarkable work on China by V. Richtofen, he give. (vol. i. p. 97) the following description of the dust atmosphere of the Loes country, China, which, it seems to me, bears upon the question of the influence of dust on the appearance of the sun and sky, the question now under discussion.

"All these, and other similar operating causes, give rise to that dust atmosphere (Staubatmosphäre) so characteristic of Central Asia, and still more particularly of the Loes District. Even during nearly complete calms the air is often for many days yellow and opaque. The view is completely hemmed in, and the sun appears merely as a dull bluish disk. More markedly is this character presented by these peculiar dust-storms so well known to travellers visiting Tien-tsin and Peking, and even more so to those who travel in the interior of the north-western provinces of China. The wind then blows from Central Asia; when it acquires motion, everything becomes coated with a fine, yellowish dust coating.

"In Shensi, where the atmosphere is but rarely clear and transparent, the whole landscape has a yellow tint; streets, houses, trees and crops, even the traveller one meets on the road, and the air itself, one and all are yellow-coloured."

He also cites Johnson's "Journey to Ilchi, the Capital of Kotan" (R. Geogr. Soc. xxxvii. I867, p. 5), as bearing on this same character of those dry, dusty atmospheres.

Dublin, January 7 J. P. O'REILIY

\section{Electric Shadows}

ON reading Prof. Thompson's communication to NATURE of the $13^{\text {th }}$ ult. (p. 156 ), giving the result of Prof. Righi's researches on the production of electric shadows in air at the ordinary pressure, I at once endeavoured to repeat the experiments with such simple means as were at hand. Two sticks of sealing-wax stuck to a small iron stand sufficed to support a long, big headed pin and the screen or object for casting the shadows. Instead of a plate of ebonite I used a cake of resin of six inches diameter, which serves ordinarily for the production of Lichtenberg's 